\title{
Corynebacterium diphtheriae as an emerging pathogen in nephrostomy catheter-related infection: evaluation of traits associated with bacterial virulence
}

Correspondence

Ana L. Mattos-Guaraldi guaraldi@pq.cnpq.br or guaraldi@uerj.br

Received 20 April 2009 Accepted 21 July 2009
Débora L. R. Gomes, ${ }^{1} \dagger$ Carlos A. S. Martins, ${ }^{1,2} \dagger$ Lúcia M. D. Faria, ${ }^{2}$ Louisy S. Santos, ${ }^{1}$ Cintia S. Santos, ${ }^{1}$ Priscila S. Sabbadini, ${ }^{1}$ Mônica C. Souza, ${ }^{1}$ Gabriela B. Alves, ${ }^{1}$ Ana C. P. Rosa, ${ }^{1}$ Prescilla E. Nagao, ${ }^{3}$ Gabriela A. Pereira, ${ }^{1}$ Raphael Hirata, Jr ${ }^{1}$ and Ana L. Mattos-Guaraldi ${ }^{1}$

${ }^{1}$ Laboratory of Diphtheria and Corynebacteria of Medical Relevance, Faculty of Medicine, University of the State of Rio de Janeiro, UERJ, Rio de Janeiro, RJ, Brazil

${ }^{2}$ Hospital Infection Control Committee, National Cancer Institute, INCA, Health Ministry, Rio de Janeiro, RJ, Brazil

${ }^{3}$ Roberto Alcantara Gomes Biology Institute, University of the State of Rio de Janeiro, UERJ, Rio de Janeiro, RJ, Brazil

Corynebacterium diphtheriae still represents a global medical challenge, particularly due to the significant number of individuals susceptible to diphtheria and the emergence of non-toxigenic strains as the causative agents of invasive infections. In this study, we characterized the clinical and microbiological features of what we believe to be the first case of $C$. diphtheriae infection of a percutaneous nephrostomy catheter insertion site in an elderly patient with a fatal bladder cancer. Moreover, we demonstrated the potential role of adherence, biofilm formation and fibrin deposition traits in C. diphtheriae from the catheter-related infection. Non-toxigenic C. diphtheriae isolated from the purulent discharge (named strain BR-CAT5003748) was identified by the API Coryne system (code 1010 324) and a multiplex PCR for detection of $d t x R$ and tox genes. Strain BRCAT5003748 showed resistance to oxacillin, ceftazidime and ciprofloxacin. In experiments performed in vitro, the catheter isolate was classified as moderately hydrophobic and as moderately adherent to polystyrene surfaces. Glass provided a more effective surface for biofilm formation than polystyrene. Micro-organisms adhered to $\left(>1.5 \times 10^{6}\right.$ c.f.u. $)$ and multiplied on surfaces of polyurethane catheters. Microcolony formation (a hallmark of biofilm formation) and amorphous accretions were observed by scanning electron microscopy on both external and luminal catheter surfaces. Micro-organisms yielded simultaneous expression of localized adherence-like and aggregative-like (LAL/AAL) adherence patterns to HEp-2 cells. Interestingly, the coagulase tube test resulted in the formation of a thin layer of fibrin embedded in rabbit plasma by the non-toxigenic BR-CAT5003748 strain. In conclusion, C. diphtheriae should be recognized as a potential cause of catheter-related infections in at-risk populations such as elderly and cancer patients. LAL/AAL strains may be associated with virulence traits that enable $C$. diphtheriae to effectively produce biofilms on catheter surfaces. Biofilm formation and fibrin deposition could have contributed to the persistence of $C$. diphtheriae at the infected insertion site and the obstruction of the nephrostomy catheter.
†These authors contributed equally to this work.

Abbreviations: AAL, aggregative-like; GBS, group B streptococcus; LAL, localized adherence-like.

\section{INTRODUCTION}

Infections due to bacteria that form biofilms are a clinical problem (Donlan, 2001; Rao et al., 2008). The surfaces of indwelling medical devices are an excellent platform for the formation of life-threatening infections. Studies 
(Christensen et al., 1982; Marrie \& Costerton, 1984) on the morphology of bacterial adherence to catheter lumen and external surfaces in vitro and in vivo showed abundant 'amorphous deposited substances' surrounding bacteria adherent to these surfaces. Biofilm-producing strains demonstrated an increased adherence to plastic surfaces as compared with non-biofilm-producing strains. Microorganisms from exogenous sources (such as the hands of personnel) or microflora indigenous to patients invade via the catheter insertion wound and migrate along the external catheter surface, eventually colonizing the catheter segment (Franson et al., 1984).

Non-diphtherial corynebacteria have been reported to be infecting pathogens or copathogens in at-risk populations such as immunocompromised patients and patients with indwelling medical devices (Cavendish et al., 1994; Esteban et al., 1999; Wang et al., 2001; Dobler \& Braveny, 2003; Schiffl et al., 2004; Lee et al., 2005; Teixido et al., 2007; Dalal \& Likhi, 2008).

Corynebacterium diphtheriae infections represent a global medical challenge, particularly due to the significant rise in the percentage of adults susceptible to diphtheria (MattosGuaraldi et al., 2001) and the emergence of non-toxigenic strains as the causative agents of endocarditis and other systemic infections (Hirata et al., 2008). This pathogen is also becoming successful in colonizing and persisting in the hospital environment (Mattos-Guaraldi et al., 2001). C. diphtheriae is an uncommon cause of catheter-related infection and to our knowledge it has not been previously reported in the medical literature.

As a consequence of the awareness of severe $C$. diphtheriae infections, what we believe to be the first case of percutaneous nephrostomy catheter infection associated with $C$. diphtheriae came to our attention for further bacterial differentiation and determination of diphtheria toxin production. We characterized the clinical and microbiological features of this infection at the catheter insertion site of an elderly patient with neoplastic disease. Moreover, the study was undertaken to determine the ability of $C$. diphtheriae to deposit fibrin, to adhere to various substrates, and also to form biofilm.

\section{METHODS}

Clinical features. In December 2006, a 73-year-old man was admitted to the National Cancer Institute-INCA, Rio de Janeiro, Brazil, with a papillary urothelial carcinoma and bladder with diminished volume capacity (Ash grade II). A transurethral resection was performed. After 3 months, both haematuria and urinary incontinence persisted and a new CT scan showed bilateral pyelocaliceal dilation and reduction in size of both kidneys. The proposal for a radical cystectomy was frustrated due to comorbilities: severe malnutrition (weight loss of $15.8 \%$ within 3 months), smoking history (56 pack years), hypertension, diabetes mellitus and advanced age. He underwent percutaneous nephrostomy and radiotherapy consisting of $65 \mathrm{~Gy}$ given over a 35-week period. Sixteen months later, the patient was admitted into the intensive care unit for the replacement of the nephrostomy catheter due to malfunction. He was anaemic (haemoglobin $4.8 \mathrm{~g} \mathrm{dl}^{-1}$ ), uraemic (blood urea nitrogen $=59.8 \mathrm{mg} \mathrm{dl}^{-1}$; creatinine $=4.68 \mathrm{mg} \mathrm{dl}^{-1}$ ) and hypoalbuminaemic $\left(1.7 \mathrm{~g} \mathrm{dl}^{-1}\right)$. Haematological analysis showed leukocytosis with high neutrophil counts (14300 cells $\mu^{-1}$ with $87 \%$ neutrophils) and lymphopenia $(6.0 \%)$. The urine was dark yellow and turbid with numerous red blood cells, rare polymorphonuclear cells, Grampositive cocci and irregular Gram-positive rods. Antibiotic therapy with meropenem was started empirically. Bacterial cultures of the urine revealed growth $\left(1 \times 10^{5}\right.$ c.f.u. $\left.\mathrm{ml}^{-1}\right)$ of Streptococcus agalactiae (group B streptococcus, GBS). Signs of local infection at the ostium of the nephrostomy catheter were also noticed and the purulent discharge was Gram-stained and cultured. Bacterioscopic examination of the secretion revealed rare polymorphonuclear cells and rare irregular Gram-positive rods, while culture was positive for $C$. diphtheriae subsp. mitis and GBS. One set of blood cultures was performed and gave negative results. Specific antibiotic therapy was started with ampicillin for 10 days. The patient presented with persistent haemodynamic instability and anaemia, and evolved to acute myocardial infarction. Transurethral resection and cystostomy for withdrawal of intravesical clots were performed. The patient was discharged from the intensive care unit on the 10th day, and discharged from the hospital on the 17th day. Three weeks later, another replacement of the nephrostomy catheter was necessary due to obstruction. Microscopic analysis of the clinical sample obtained from the ostium of the nephrostomy showed some neutrophils, some Gram-negative bacilli and rare Gram-positive cocci. Culture showed the presence of Escherichia coli and Enterococcus faecalis; both were multisensitive to all the antibiotics tested. The bacterial cultures for $C$. diphtheriae gave negative results. Six months later, death occurred due to cancer progression.

Micro-organisms and identification procedures. Positive bacterial culture for irregular Gram-positive rods was preliminarily characterized by colonial morphology, pigmentation, haemolysis and DNase activity. Phenotypic characterization of Corynebacterium-like colonies was performed by conventional biochemical assays and the semi-automated API Coryne System (bioMérieux) with the API web decoding system (www.apiweb.biomerieux.com) (Efstratiou \& George, 1999; Funke \& Bernard, 2007; Pimenta et al., 2008b).

A multiplex PCR using three different primer pairs developed for detection of $C$. diphtheriae infection and differentiation between toxigenic and non-toxigenic strains was performed based on protocols described elsewhere: two primer pairs targeted to domains $\mathrm{A}$ and $\mathrm{B}$ of the tox gene and a third primer pair targeted to a region of the $d t x R$ gene (Pimenta et al., 2008a).

The non-toxigenic C. diphtheriae type strain ATCC 27010 [C7 s (-) tox- (NCTC 11397)] and the homologous toxigenic ATCC 27012 strain (tox + ) from the American Type Culture Collection (USA), toxigenic strain CDC E-8392 (autoaggregative, highly hydrophobic, non-glass adherent, non-sucrose-fermenting) and toxigenic strain 241 (non-autoaggregative, weakly hydrophobic, glass adherent, sucrosefermenting) were used as experimental controls.

Stock cultures in $10 \%$ skim milk with $25 \%$ added glycerol were maintained at $-70{ }^{\circ} \mathrm{C}$ and recovered as required by cultivation in trypticase soy broth (TSB) (Hirata et al., 2004).

Antimicrobial susceptibility testing. The disc diffusion method was performed in accordance with the guidelines provided by the Clinical and Laboratory Standards Institute (CLSI). Because of the absence of accepted breakpoints for coryneform bacteria into interpretative categories, those established by CLSI guidelines for organisms other than Haemophilus species and Neisseria gonorrhoeae were used (CLSI, 2007). The breakpoints for Staphylococcus aureus were considered for penicillin $\mathrm{G}$, ampicillin and oxacillin (Pereira et al., 2008). 
Bacterial autoaggregation, and adherence to $\boldsymbol{n}$-hexadecane assays. Bacterial spontaneous autoaggregation in TSB and the assays evaluating bacterial adhesion to $n$-hexadecane (BATH) were performed by methods previously described (Mattos-Guaraldi \& Formiga, 1991; Mattos-Guaraldi et al., 1999b). Spontaneously autoaggregating strains and/or those with BATH values $\geqslant 50 \%$ were considered to be highly hydrophobic, and non-aggregating strains or those with $30 \% \leqslant$ BATH values $<50 \%$ were considered to be moderately hydrophobic.

Biofilm formation on polystyrene surfaces. Biofilm formation was determined quantitatively in 96-well flat-bottomed polystyrene microtitre plates based on standard procedures (Stepanovic et al., 2000). Briefly, $200 \mu \mathrm{l}$ bacterial suspensions with an $\mathrm{OD}_{570}$ of 0.2 were applied to microplate wells. Negative controls contained TSB only. After incubation for $24 \mathrm{~h}$ at $37^{\circ} \mathrm{C}$, the content of each well was aspirated and washed three times with $200 \mu \mathrm{l}$ PBS (pH 7.2). The remaining attached bacteria were fixed with $200 \mu$ l $99 \%$ methanol and stained with $2 \%$ crystal violet. The bound dye was then solubilized with $160 \mu \mathrm{l} 33 \%$ glacial acetic acid and the $\mathrm{OD}_{570}$ of the solution was measured. The cut-off optical density $\left(\mathrm{OD}_{c}\right)$ was defined as the mean optical density of the negative control. All strains were classified as non- $\left(0\right.$ : $\left.\mathrm{OD} \leqslant \mathrm{OD}_{\mathrm{c}}\right)$, weakly $\left(+: \mathrm{OD}_{\mathrm{c}}<\mathrm{OD} \leqslant 2 \times\right.$ $\left.\mathrm{OD}_{\mathrm{c}}\right)$, moderately $\left(++: 2 \times \mathrm{OD}_{\mathrm{c}}<\mathrm{OD} \leqslant 4 \times \mathrm{OD}_{\mathrm{c}}\right)$ or strongly $\left(+++: 4 \times \mathrm{OD}_{\mathrm{c}} \leqslant \mathrm{OD}\right)$ adherent, based upon the ODs of bacterial films. Each assay was performed in triplicate and repeated three times.

Biofilm formation on surfaces of glass tubes. Micro-organisms were inoculated in glass tubes $(13 \times 100 \mathrm{~mm})$ containing $4 \mathrm{ml}$ TSB and incubated for $48 \mathrm{~h}$ at $37{ }^{\circ} \mathrm{C}$ without shaking. The tubes were gently shaken for $5 \mathrm{~s}$, and the supernatants containing bacterial cells that were not adherent to the surfaces of the glass tubes were discarded. TSB $(4 \mathrm{ml})$ was then added, and the tubes were reincubated for $48 \mathrm{~h}$. This procedure was repeated twice. The glassadherent bacteria created a confluent coat of cells on the sides of the tube (Mattos-Guaraldi \& Formiga, 1991).

In vitro model of catheter infection. Polyurethane 16-gauge percutaneous nephrostomy catheters (Intracath; Deseret Pharmaceutical) were used in the in vitro model system for evaluation of bacterial adherence and biofilm formation on catheter surfaces. Sterile $4 \mathrm{~cm}$ segments of polyurethane catheters were immersed for $24 \mathrm{~h}$ in $10^{6}$ c.f.u. bacteria $\mathrm{ml}^{-1}$ suspended in TSB medium (Franson et al., 1984).

Quantitative catheter culture and semiquantitative roll plate technique. Catheter segments infected in vitro with strain BRCAT5003748 were cultured by using a quantitative (Dooley et al., 1996) and a semiquantative (Maki et al., 1977) method on Columbia agar medium supplemented with $5 \%$ sheep blood for $24 \mathrm{~h}$ at $37^{\circ} \mathrm{C}$.

Scanning electron microscopy. In vitro specimens (sections of glass coverslips and polyurethane catheters) were fixed in $2.5 \%$ glutaraldehyde, post-fixed in $1 \%$ osmium tetroxide and dehydrated in a graded series of ethanol. Subsequently, catheter segments were subjected to critical point drying with carbon dioxide, covered with gold-palladium to a $10 \mathrm{~nm}$ layer and examined with a JEOL JSM 5310 scanning electron microscope. Sterile unused polyurethane catheters were also processed by scanning electron microscopy directly upon removal from commercial packaging. Catheter segments infected in vitro with Staphylococcus epidermidis were used as positive controls (Franson et al., 1984).

HEp-2 cell adherence pattern assays. Patterns of adherence of bacteria to HEp-2 cells were assayed by previously described methods (Hirata et al., 2004, 2008). Briefly, adherence assays were performed within semiconfluent HEp-2 cells grown on circular coverslips in
DMEM (Sigma) supplemented with $5 \%$ fetal calf serum, $50 \mu \mathrm{g}$ gentamicin $\mathrm{ml}^{-1}, 2.5 \mu \mathrm{g}$ amphotericin $\mathrm{B} \mathrm{ml}^{-1}$ and $0.5 \%$ L-glutamine at $37{ }^{\circ} \mathrm{C}$ in a $5 \% \mathrm{CO}_{2}$ atmosphere. Micro-organisms were washed twice in $10 \mathrm{mM}$ PBS ( $\mathrm{pH} 7.2$ ), resuspended in DMEM to a concentration of $10^{7}$ c.f.u. $\mathrm{ml}^{-1}$, and used in adherence assays $(6 \mathrm{~h})$. Giemsa-stained coverslips were examined by bright-field microscopy.

Bacterial interaction with rabbit plasma. The coagulase test was based on procedures described for S. aureus strains (Christensen et al., 1983). EDTA-chelated rabbit plasma was obtained from Ebe Farma Biológica e Agropecuária LTDA (Rio de Janeiro, RJ, Brazil). Tests were performed in $9 \times 100 \mathrm{~mm}$ glass test tubes with chelated rabbit plasma diluted in PBS to $1: 4$. Since a positive test for coagulase production results in a clotting of the rabbit plasma, any degree of clotting was considered as positive due to the absence of parameters for $C$. diphtheriae in this assay. Results were reported across a range $0-4+$; 0 meaning the plasma remained liquid (no coagulase activity) and $4+$ meaning the plasma completely hardened (the consistency of an agar) due to strong coagulase activity. The coagulase reaction was read until $24 \mathrm{~h}$ post-incubation at $37^{\circ} \mathrm{C}$. All ' $O$ ' results were held at room temperature for an additional $24 \mathrm{~h}$ incubation. Positive $(4+, S$. aureus) and negative (0, S. epidermidis) controls were included in the study.

\section{RESULTS AND DISCUSSION}

Strain BR-CAT5003748 produced the numerical pattern 1010324 In the API Coryne system, which was identified by the API Coryne database as $C$. diphtheriae subsp. mitis with $95.9 \%$ probability $(T=0.99)$. The primer set for the tox gene used in the multiplex PCR assay gave negative results (Fig. 1). Strain BR-CAT5003748 was susceptible to ampicillin, cefepime, ceftriaxone, erythromycin, imipenem, vancomycin, cefazolin, gentamicin and penicillin $G$ and resistant to oxacillin, ciprofloxacin and ceftazidime.

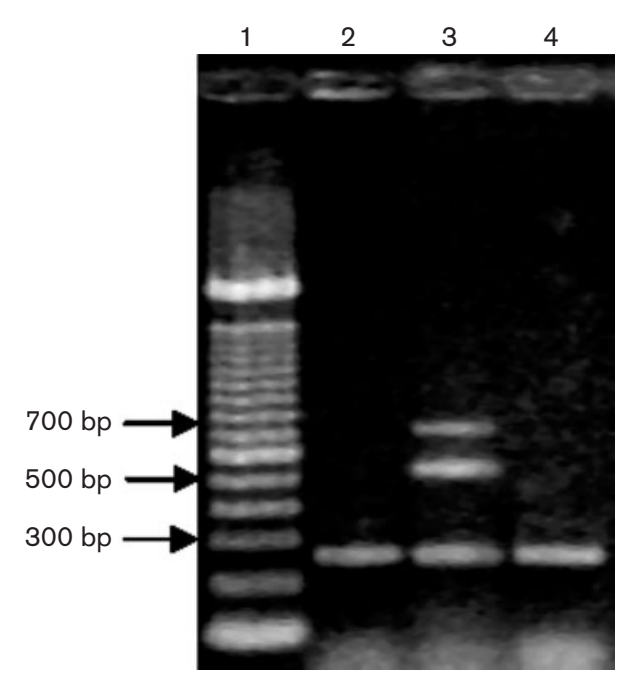

Fig. 1. Results of multiplex PCR for identification of $C$. diphtheriae and detection of the tox gene. Lanes: 1, 100 bp DNA ladder; 2, BR-CAT5003748 test strain; 3, ATCC 27012 toxigenic control strain; 4, ATCC 27010 non-toxigenic control strain. 
A review of the current literature indicated that polymicrobial infections occur frequently $(15 \%)$ in immunocompromised patients with cancer (Elting et al., 1986; Rolston et al., 2007). Compared with monomicrobial infections, polymicrobial infections in both neutropenic and non-neutropenic patients are associated with greater morbidity and mortality. The authors emphasized that there is only limited information concerning the spectrum and microbiology of these infections. Data regarding polymicrobial infections and nonbacteraemic infections are often incomplete or not provided at all. For cancer patients, the array of potential pathogens is wide, and opportunistic agents should be taken into account in addition to conventional micro-organisms. The list is constantly growing. Specific microbiological diagnosis is barely established because of the lack of clear distinction between colonization and infection. There is no clear definition of opportunistic infection, and the differentiation between conventional pathogens and opportunistic agents is not well defined (Klastersky \& Aoun, 2004). Many laboratories do not process culture specimens from voided or catheterized urine, drainage from intra-abdominal or pelvic collections, or infected surgical sites when multiple organisms are recovered. In most instances, these culture results are simply reported as 'normal site flora' or 'contaminated specimens', without identification of the organisms to the species level, including Corynebacterium species.

Accordingly, the virulence capacity of Corynebacterium species should not be underestimated, particularly in highrisk patients (Klastersky \& Aoun, 2004; Oudiz et al., 2004). Fortunately, in most of the reported cases of catheterrelated infections caused by non-diphtherial corynebacteria, the patients were treated successfully with antibiotics and without removal of the catheter (Wang et al., 2001; Dobler \& Braveny, 2003; Oudiz et al., 2004; Schiffl et al., 2004; Lee et al., 2005; Teixido et al., 2007; Dalal \& Likhi, 2008). In contrast to most of the reported cases of catheterrelated infections caused by non-diphtherial corynebacteria species, in the case reported here removal of the catheter was mandatory.

The isolation of non-toxigenic C. diphtheriae and GBS strains from the ostium of a percutaneous nephrostomy catheter provided evidence that both micro-organisms can be implicated in catheter-related infections. It may be the case that these two pathogens had a synergistic effect on the development of a co-infection.

GBS infection causes substantial morbidity and mortality among adults, particularly in elderly persons (mean age 71 years), those with significant underlying diseases such as cancer, those with a prior history of urinary tract infections or with an indwelling urinary catheter, and those with anatomical abnormalities of the urinary tract. Urinary tract infection is the clinical diagnosis for $39 \%$ of adults $>70$ years of age with invasive GBS disease. GBS has been associated with the infection of intravenous catheters, arterial lines and an intravenous pacemaker wire. However, co-infection with $S$. aureus is common in patients who have a GBS infection that is associated with the presence of an intravascular device (Farley, 2001). Since GBS was isolated from the catheter insertion site, and from the urine of the patient, a pathogenic role of GBS is feasible.

While lower bacterial counts at the catheter insertion site argue more for colonization than infection, this last possibility cannot be excluded, particularly among immunocompromised patients. This motivated the analysis of virulence factors exhibited by the $C$. diphtheriae BRCAT5003748 strain that could have effectively contributed to the establishment of the catheter-related infection.

Biofilm formation is a well-known pathogenic mechanism in device-related infections in hospitals (Stewart \& Costerton, 2001). Some bacteria, including non-diphtherial corynebacteria species (Marrie \& Costerton, 1984; Soriano et al., 1993, 2008; Olson et al., 2002; Kwaszewska et al., 2006; Suzuki et al., 2007), have a natural tendency to adhere to available biotic and/or abiotic surfaces and to form biofilms.

The developmental biology of biofilm formation can be characterized into three stages: the initial attachment, development of microcolony formation, and detachment (O'Toole et al., 2000). The general findings from the literature indicate that two properties are often associated with biofilm-producing bacteria, namely the increased synthesis of exopolysaccharide and the development of antibiotic resistance (Costerton et al., 1999; Olson et al., 2002; Rao et al., 2008). The presence of exopolysaccharide surrounding bacteria in clinical specimens has been observed to be associated with symptomatic catheter infections. Other factors such as the presence of trace metals (Aranha et al., 1982) and hydrophobicity (Rosenberg, 1981) may also be important in such interactions.

Little is known concerning biofilm formation by $C$. diphtheriae. In earlier studies, different levels of adherence to glass surfaces were observed among $C$. diphtheriae strains. Most of the strains $(71 \%)$ exhibiting lower haemagglutinating activity were predominantly effective adherers to glass surfaces (Mattos-Guaraldi \& Formiga, 1991). Bacterial autoaggregating properties in liquid media and hydrophobicity were also observed among C. diphtheriae strains (Mattos-Guaraldi et al., 1999b). C. diphtheriae strains tested were able to adhere to negatively charged plastic (polystyrene) surfaces as recently observed with Corynebacterium urealyticum (Soriano et al., 2008). For lipophilic skin corynebacteria, autoaggregation in liquid media and hydrophobicity were statistically connected with biofilm formation on solid surfaces (Kwaszewska et al., 2006). For C. diphtheriae strains, autoaggregation in liquid media and hydrophobicity were related to biofilm formation on polystyrene surfaces, but not to biofilm formation on positively charged glass surfaces (MattosGuaraldi \& Formiga, 1991). 
Table 1. C. diphtheriae adhesive properties to different substrates

BATH, bacterial adherence to $n$-hexadecane; LA, localized adherence, microcolonies attach to small areas on the cells; DA, diffuse adherence, bacteria cover the tissue culture cells uniformly; AA, autoaggregating bacteria grown in liquid medium; - , negative; + , positive; ++ , moderately positive; +++ , strongly positive.

\begin{tabular}{|c|c|c|c|c|c|}
\hline \multirow[t]{2}{*}{ Strain } & \multicolumn{2}{|c|}{ Biofilm formation } & \multicolumn{2}{|c|}{ Hydrophobicity } & \multirow[t]{2}{*}{ Pattern of adherence to HEp-2 cells } \\
\hline & Glass & Polystyrene & $\mathbf{A A}$ & $\%$ BATH & \\
\hline 241 & $+++^{*}$ & ++ & - & 33 & LA \\
\hline CDC E-8392 & $-\dagger$ & ++ & + & 51 & $\mathrm{DA}$ \\
\hline
\end{tabular}

${ }^{\star}$ Confluent coat of bacterial cells on the sides of the tubes and localized adherence on glass surfaces where the culture medium is in contact with the air. $\dagger$ No visible adherence.

Amorphous deposited substances or glycocalyx have been noted covering C. diphtheriae cells (Moreira et al., 2003). Previous studies indicated the presence of exopolysaccharides on the surfaces of $C$. diphtheriae cells (Mattos-Guaraldi et al., 1999a) which can be also produced by organisms such as coagulase-negative staphylococci (Christensen et al., 1982, 1983) and Pseudomonas aeruginosa (Chan et al., 1984). C. diphtheriae strains exhibited surface saccharide ligands such as $\mathrm{N}$-acetylglucosamine, $\mathrm{N}$-acetylgalactosamine, galactose, mannose-like and sialic acid residues, but at different levels. The sialic acid-rich regions contribute to creating a negative charge on the surface of the cells. The presence of an exposed sialic acid moiety was predominantly observed on surfaces of glass-adherent $C$. diphtheriae (Mattos-Guaraldi et al., 1999b). Moreover, C. diphtheriae strains seemed to withstand oxidative environmental stress partly due to their biofilm-forming abilities (Silva De Souza et al., 2003). The expression of exopolysaccharides on the bacterial cells and the ability to adhere to glass surfaces were drastically decreased when $C$. diphtheriae strains were submitted to growth under ironlimiting conditions (Moreira et al., 2003).
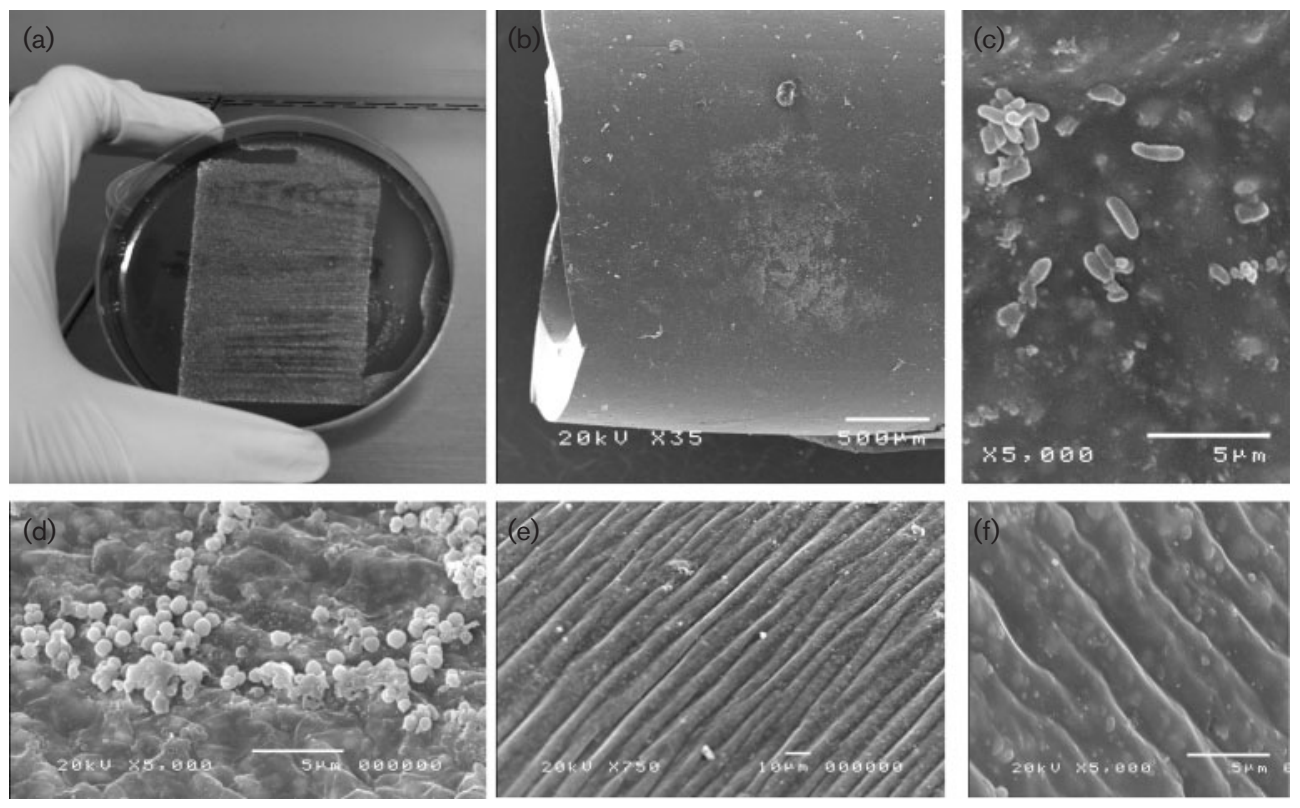

Fig. 2. C. diphtheriae BR-CAT5003748 biofilm production on the surface of an in vitro prepared polyurethane percutaneous nephrostomy catheter. (a) Segments of polyurethane catheter semiquantitative culture exhibiting confluent growth of $C$. diphtheriae BR-CAT5003748; (b, c) scanning electron micrographs of biofilm formation on the outer surface of a bisected polyurethane catheter; (d) accretions on catheters infected in vitro with $S$. epidermidis (positive control) showing coccoid bacteria within a confluent biofilm; $(e, f)$ the surface of an unused sterile polyurethane percutaneous nephrostomy catheter, characterized by multiple gentle linear irregularities. 
For $C$. diphtheriae, the mechanisms by which bacterial colonization of catheters occurs have yet to be defined. The studies highlighted above have examined factors which may relate to this phenomenon. Like other $C$. diphtheriae strains, the non-toxigenic BR-CAT5003748 strain was weakly hydrophobic and unable to autoaggregate in liquid media but was capable of adhering to polystyrene and glass surfaces (Table 1).

Segments of polyurethane catheters were colonized in vitro by the $C$. diphtheriae BR-CAT5003748 strain. A large amount of biofilm material was evident (Figs 2 and 3). For $S$. epidermidis strains used as a positive control, in some areas the cocci were coated with slime (Fig. 2). Similarly, for $C$. diphtheriae, bacterial cells coated with slime (condensed glycocalyx) were also observed on polyurethane surfaces (Fig. 3). Evaluation of adherence and viability of micro-organisms on polyurethane catheter segments by the semiquantitative roll plate method ( $>15$ c.f.u.) and by the quantitative catheter culture assays $\left(>1.5 \times 10^{6}\right)$ showed that viable cells of the non-toxigenic $C$. diphtheriae BR-CAT5003748 strain extensively adhered to and multiplied on the surfaces of polyurethane catheters (Fig. 2).

Fig. 3 illustrates microcolony formation on a luminal catheter surface (Fig. 3a, b) and on a glass surface (Fig. 3c). Amorphous accretions and micro-organisms coated by slime were observed on the polyurethane surface, but not on the glass. Therefore, strain BR-CAT5003748 showed properties similar to those of other human pathogens that are biofilm producers. As for Acinetobacter baumannii (Rao et al., 2008), we have observed the ability of the BRCAT5003748 strain to attach to and form microcolonies on glass surfaces. As for non-diphtherial Corynebacterium species (Marrie \& Costerton, 1984; Soriano et al., 1993), cells of C. diphtheriae BR-CAT5003748 also appeared to form matrix-enclosed microcolonies on in vitro colonized polyurethane surfaces.

Different catheter materials have varying affinities for bacterial adherence (Franson et al., 1984). Polyurethane implanted subcutaneously in mice was accompanied by an infiltration of erythrocytes and subsequent haemolysis possibly resulted from a positive charge associated with this plastic, attracting negatively charged cells (Rigdon, 1970). In this study, $C$. diphtheriae produced biofilm on both the luminal and external surfaces of polyurethane catheters. Similar to observations with other Gram-positive pathogens, the gentle nature of the surface irregularities probably does not fully account for trapping $C$. diphtheriae on polyurethane catheter surfaces. In accordance with previous observations with glass surfaces (Mattos-Guaraldi \& Formiga, 1991), adherence of $C$. diphtheriae to polyurethane may be partially explained by a positive electric charge associated with this polymer. Moreover, the amorphous deposited substances or glycocalyx noted surrounding $C$. diphtheriae microcolonies on the surfaces of polyurethane catheters suggest that the bacteria may produce or attract substances that strengthen their attachment to inert surfaces in vitro.
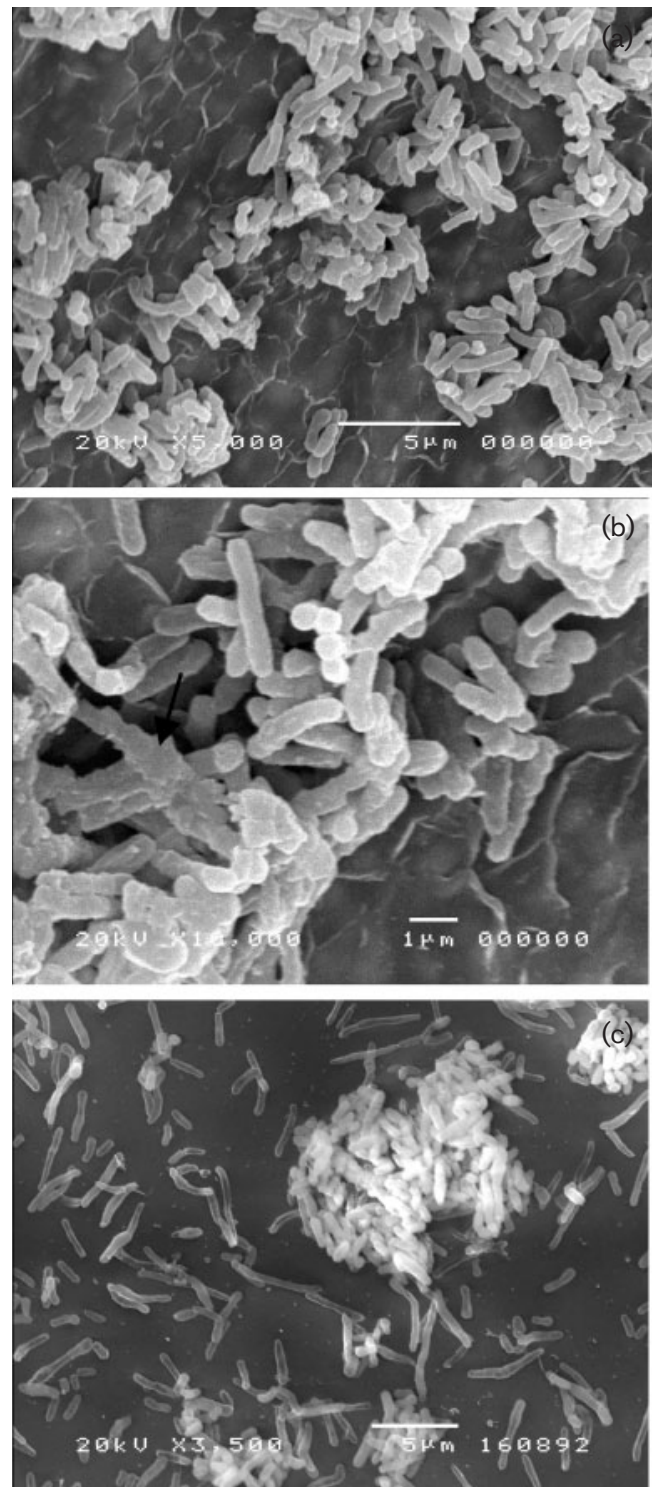

Fig. 3. Scanning electron micrographs illustrating biofilm formation by $C$. diphtheriae on the inner surface of a bisected polyurethane catheter and on a glass surface. (a) A large amount of biofilm material exhibiting bacterial microcolonies and amorphous material on the catheter surface is evident. (b, c) Formation of microcolonies on the surfaces of a polyurethane catheter (b) and a glass coverslip (c). Bacterial cells coated with slime (condensed glycocalyx) were observed on the polyurethane surface (arrow).

Biofilm formation is a common phenomenon in the pathogenesis of enteroaggregative E. coli (EAEC). Multiple genes associated with biofilm formation are regulated by aggR, a global regulator of EAEC virulence (Mohamed et al., 2007). The presence of atypical adherence patterns has been linked to new E. coli virulence categories. The localized adherence-like (LAL) pattern is characterized by the presence of less-compact microcolonies or clusters of bacteria in a few cells observed only in tests with prolonged 

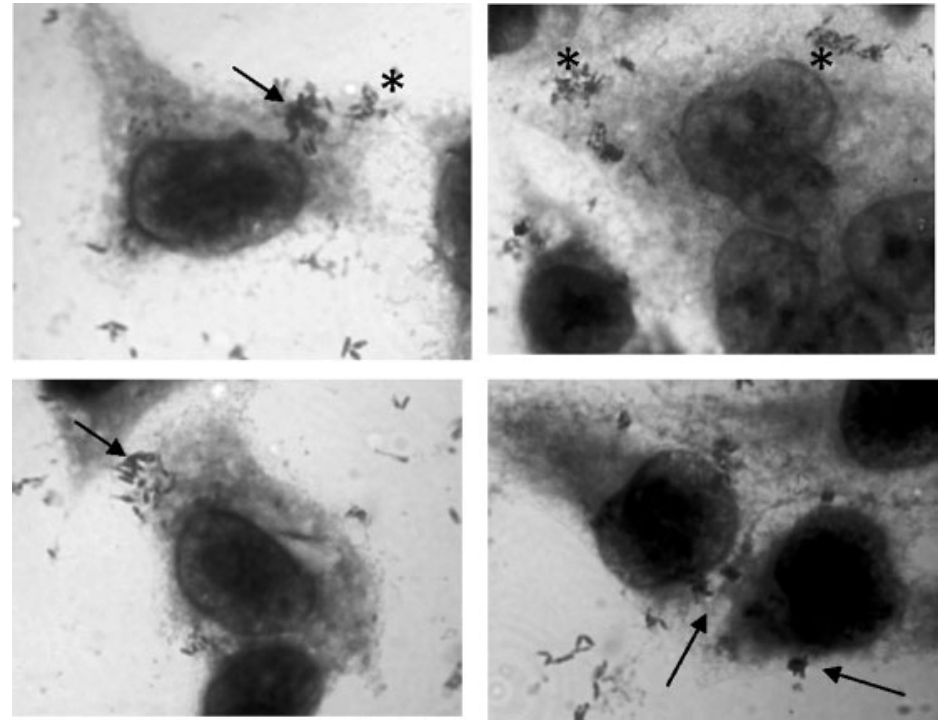

Fig. 4. Micrographs of HEp-2 cell adherence assay ( $6 \mathrm{~h}$ incubation) demonstrating a mixed LAL/AAL pattern exhibited by the biofilmproducing $C$. diphtheriae subsp. mitis BRCAT5003748 strain isolated from the catheter insertion site. LAL (arrows), bacteria attached to localized areas of the HEp-2 cells, forming loose microcolonies; AAL (asterisk), bacteria aligned in parallel rows adhered to both tissue culture cells and glass. Magnification $\times 1000$. incubation periods (6 h) (Scaletsky et al., 1999). E. coli strains isolated from immunocompromised patients may express simultaneously features of three (localized, aggregative and diffuse) adherence patterns (Polotsky et al., 1997) while some $E$. coli strains not belonging to any recognized classes of diarrhoeagenic E. coli may present a mixed aggregative-like (AAL)/LAL pattern (Bouzari et al., 1994).

Differing degrees of attachment to HEp-2 monolayers with a predominance of localized and diffuse adherence patterns were previously observed for $C$. diphtheriae strains isolated from throat and skin lesions (Hirata et al., 2004). Recent studies also indicated a pathogenic role of aggregativeadhering (AA) $C$. diphtheriae in invasive disease (Hirata et al., 2008). Previous studies suggested biofilm-forming ability among $C$. diphtheriae strains expressing the LAL (Mattos-Guaraldi \& Formiga, 1991; Hirata et al., 2004) and AAL (Mattos-Guaraldi \& Formiga, 1998) patterns.

In the present study, microcolony formation (a hallmark of biofilm formation) by strain BR-CAT5003748 was observed on epithelial cell surfaces as well as on polyurethane and glass surfaces. Micro-organisms were found attached to localized areas of the HEp-2 cells, forming loose microcolonies, which characterizes a LAL pattern. BR-CAT5003748 cells also adhered to the epithelial cell surface, to the glass substratum, and to each other in a distinctive stacked-brick formation, but without the typical honeycomb formation, which characterizes an AAL adherence pattern (Fig. 4). For EAEC, this atypical AAL adherence pattern was named B type (Wakimoto et al., 2004). Therefore, strain BR-CAT5003748 expressing biofilm-forming ability on the surfaces of polyurethane catheters showed simultaneous features of LAL and AAL patterns to HEp-2 cells. Similarly to E. coli, the existence of atypical and mixed adherence patterns may indicate a new mechanism of disease production by $C$. diphtheriae.
The coagulase reaction resulted in fibrin deposition (level $2+$ ) by $C$. diphtheriae BR-CAT5003748 with formation of a large pellicle resembling a pseudomembrane formed inside the test tubes (Fig. 5). Pellicle formation was not observed for S. aureus $(4+)$ or S. epidermidis (0) control strains.

Intrinsic catheter surface properties, bacterial surface features, and perhaps coating with host substances may all play a role in bacterial attachment to catheter surfaces. Although fibrin production is one of the primary host defences against infection, a common cause of catheter malfunction is obstruction by a fibrin sheath. Catheter tips may show deposits composed of fibrin and cells occluding the inner lumen. Moreover, the encasement of fibrin,

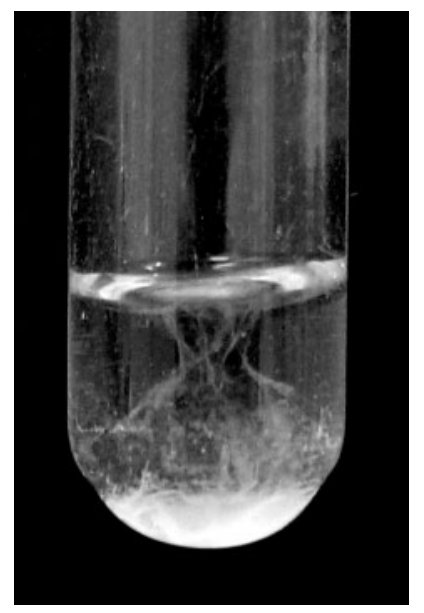

Fig. 5. Micrograph demonstrating the positive coagulase reaction of C. diphtheriae strain BR-CAT5003748. Note the formation of a large pellicle of fibrin embedded in plasma. 
plasma proteins, platelets and other undefined substances around the external catheter surface may provide a niche conducive to bacterial implantation. It is possible that fibrin deposition on the catheter can be stimulated by subclinical infection (Franson et al., 1984; BousquetRouaud et al., 1993). In addition to bacterial growth and biofilm production on luminal surfaces, fibrin deposition is a characteristic of $C$. diphtheriae strains that may contribute to catheter malfunction. Data suggest that this ability of $C$. diphtheriae may have contributed to catheter obstruction and to the establishment of both pathogens at the ostium of the nephrostomy in this study.

In conclusion, diphtheria bacilli are capable of adhering to catheters and inducing infections in susceptible hosts. C. diphtheriae may form biofilm on polyurethane catheters in vivo possibly by an adherent biofilm mode of growth as on polyurethane surfaces in vitro.

\section{ACKNOWLEDGEMENTS}

This work was supported by INCA, FAPERJ, CNPq, SR-2/UERJ, Programa de Núcleo de Excelência (PRONEX) and Programa Nacional de Pós-Doutorado-PNPD (CAPES/MEC). We also thank Wagner Oliveira Brito and Jorge Ari da Cruz for technical assistance.

\section{REFERENCES}

Aranha, H., Strachan, R. C., Arceneaux, J. E. L. \& Byers, B. R. (1982). Effect of trace metals on growth of Streptococcus mutans in a teflon chemostat. Infect Immun 35, 456-460.

Bousquet-Rouaud, R., Castex, F., Costalat, G., Bastide, M., Hedon, B., Bouanani, M., Jouvert, S. \& Mirouze, J. (1993). Factors involved in catheter obstruction during long-term peritoneal insulin infusion. Diabetes Care 16, 801-805.

Bouzari, S., Jafari, A., Farhoudi-Moghaddam, A. A., Shokouhi, F. \& Parsi, M. (1994). Adherence of non-enteropathogenic Escherichia coli to HeLa cells. J Med Microbiol 40, 95-97.

Cavendish, J., Cole, J. B. \& Ohl, C. A. (1994). Polymicrobial central venous catheter sepsis involving a multiantibiotic-resistant strain of Corynebacterium minutissimum. Clin Infect Dis 19, 204-205.

Chan, R., Lam, J. S., Lam, K. \& Costerton, J. W. (1984). Influence of culture conditions on expression of the mucoid mode of growth of Pseudomonas aeruginosa. J Clin Microbiol 19, 8-16.

Christensen, G. D., Simpson, W. A., Bisno, A. L. \& Beachey, E. H. (1982). Adherence of slime-producing strains of Staphylococcus epidermidis to smooth surfaces. Infect Immun 37, 318-326.

Christensen, G. D., Parisi, J. T., Bisno, A. L., Simpson, W. A. \& Beachey, E. H. (1983). Characterization of clinically significant strains of coagulase-negative staphylococci. J Clin Microbiol 18, 258-269.

CLSI (2007). Methods for Antimicrobial Dilution and Disk Susceptibility Testing of Infrequently Isolated or Fastidious Bacteria, pp. 4-6. Approved Guideline. CLSI document M45-A. Wayne, PA: Clinical and Laboratory Standards Institute.

Costerton, J. W., Stewart, P. S. \& Greenberg, E. P. (1999). Bacterial biofilms: a common cause of persistent infections. Science 284, 13181322.

Dalal, A. \& Likhi, R. (2008). Corynebacterium minutissimum bacteremia and meningitis: a case report and review of literature. J Infect 56, $77-79$.
Dobler, G. \& Braveny, I. (2003). Highly resistant Corynebacterium macginleyi as cause of intravenous catheter-related infection. Eur $J$ Clin Microbiol Infect Dis 22, 72-73.

Donlan, R. M. (2001). Biofilms and device-associated infections. Emerg Infect Dis 7, 277-281.

Dooley, D. P., Garcia, A., Kelly, J. W., Longfield, R. N. \& Harrison, L. (1996). Validation of catheter semiquantitative culture technique for non staphylococcal organisms. J Clin Microbiol 34, 409-412.

Efstratiou, A. \& George, R. C. (1999). Laboratory guidelines for the diagnosis of infections caused by Corynebacterium diphtheriae and Corynebacterium ulcerans. Commun Dis Public Health 2, 250-257.

Elting, L. S., Bodey, G. P. \& Fainstein, V. (1986). Polymicrobial septicemia in the cancer patient. Medicine 65, 218-225.

Esteban, J., Nieto, E., Calvo, R., Fernandez-Robals, R., ValeroGuillen, P. L. \& Soriano, F. (1999). Microbiological characterization and clinical significance of Corynebacterium amycolatum strains. Eur J Clin Microbiol Infect Dis 18, 518-521.

Farley, M. M. (2001). Group B streptococcal disease in nonpregnant adults. Clin Infect Dis 33, 556-561.

Franson, T. R., Sheth, N. K., Rose, H. D. \& Sohnle, P. G. (1984). Scanning electron microscopy of bacteria adherent to intravascular catheters. J Clin Microbiol 20, 500-505.

Funke, G. \& Bernard, A. K. (2007). Coryneform Gram-positive rods. In Manual of Clinical Microbiology, pp. 485-514. Edited by P. R. Murray, E. J. Baron, M. A. Pfaller, J. H. Jorgensen \& R. H. Yolken. Washington, DC: American Society for Microbiology.

Hirata, R., Jr, Souza, S. M., Rocha-de-Souza, C. M., Andrade, A. F., Monteiro-Leal, L. H., Formiga, L. C. \& Mattos-Guaraldi, A. L. (2004). Patterns of adherence to HEp-2 cells and actin polymerisation by toxigenic Corynebacterium diphtheriae strains. Microb Pathog 36, 125-130.

Hirata, R., Jr, Pereira, G. A., Filardy, A. A., Gomes, D. L. R., Damasco, P. V., Rosa, A. C. P., Nagao, P. E., Pimenta, F. P. \& Mattos-Guaraldi, A. L. (2008). Potential pathogenic role of aggregative adhering Corynebacterium diphtheriae of different clonal groups in endocarditis. Braz J Med Biol Res 41, 986-991.

Klastersky, J. \& Aoun, M. (2004). Opportunistic infections in patients with cancer. Ann Oncol 15, iv329-iv335.

Kwaszewska, A. K., Brewczynska, A. \& Szewczyk, E. M. (2006). Hydrophobicity and biofilm formation of lipophilic skin corynebacteria. Pol J Microbiol 55, 189-193.

Lee, P. P., Ferguson, D. A., Jr \& Sarubbi, F. A. (2005). Corynebacterium striatum: an underappreciated community and nosocomial pathogen. J Infect 50, 338-343.

Maki, D. G., Weise, C. E. \& Sarafin, H. W. (1977). A semi-quantitative culture method for identifying intravenous-catheter-related infection. $N$ Engl J Med 296, 1305-1309.

Marrie, T. J. \& Costerton, J. W. (1984). Scanning and transmission electron microscopy of in situ bacterial colonization of intravenous and intra-arterial catheters. J Clin Microbiol 19, 687-693.

Mattos-Guaraldi, A. L. \& Formiga, L. C. D. (1991). Relationship of biotype and source to the hemagglutination and adhesive properties of Corynebacterium diphtheriae. Braz J Med Biol Res 24, 399-406.

Mattos-Guaraldi, A. L. \& Formiga, L. C. D. (1998). Bacteriological properties of a sucrose-fermenting Corynebacterium diphtheriae strain isolated from a case of endocarditis. Curr Microbiol 37, 156-158.

Mattos-Guaraldi, A. L., Cappelli, E. A., Previato, J. O., Formiga, L. C. D. \& Andrade, A. F. B. (1999a). Characterization of surface saccharides in two Corynebacterium diphtheriae strains. FEMS Microbiol Lett 170, 159-166. 
Mattos-Guaraldi, A. L., Formiga, L. C. D. \& Andrade, A. F. B. (1999b). Cell surface hydrophobicity of sucrose fermenting and nonfermenting Corynebacterium diphtheriae strains evaluated by different methods. Curr Microbiol 38, 37-42.

Mattos-Guaraldi, A. L., Formiga, L. C. D., Camello, T. C. F., Pereira, G. A., Hirata, R., Jr \& Halpern, M. (2001). Corynebacterium diphtheriae threats in cancer patients. Rev Argent Microbiol 33, 96-100.

Mohamed, J. A., Huang, D. B., Jiang, Z. D., DuPont, H. L., Nataro, J. P., Belkind-Gerson, J. \& Okhuysen, P. C. (2007). Association of putative enteroaggregative Escherichia coli virulence genes and biofilm production in isolates from travelers to developing countries. J Clin Microbiol 45, 121-126.

Moreira, L. de O., Andrade, A. F. B., Vale, M. D., Souza, S. M. S., Hirata, R., Jr, Asad, L. M. O. B., Asad, N. R., Monteiro-Leal, L. H., Previato, J. O. \& Mattos-Guaraldi, A. L. (2003). Effects of iron limitation on adherence and cell surface carbohydrates of Corynebacterium diphtheriae strains. Appl Environ Microbiol 69, 5907-5913.

Olson, M. E., Ceri, H., Morck, D. W., Buret, A. G. \& Read, R. R. (2002). Biofilm bacteria: formation and comparative susceptibility to antibiotics. Can J Vet Res 66, 86-92.

O'Toole, G., Kaplan, H. B. \& Kolter, R. (2000). Biofilm formation as microbial development. Annu Rev Microbiol 54, 49-79.

Oudiz, R. J., Widlitz, A., Beckmann, X. J., Camanga, D., Alfie, J., Brundage, B. H. \& Barst, R. J. (2004). Micrococcus-associated central venous catheter infection in patients with pulmonary arterial hypertension. Chest 126, 90-94.

Pereira, G. A., Pimenta, F. P., Santos, F. R., Damasco, P. V., Hirata, R., Jr \& Mattos-Guaraldi, A. L. (2008). Antimicrobial resistance among Brazilian Corynebacterium diphtheriae strains. Mem Inst Oswaldo Cruz 103, 507-510.

Pimenta, F. P., Hirata, R., Jr, Rosa, A. C. P., Milagres, L. G. \& MattosGuaraldi, A. L. (2008a). A multiplex PCR assay for simultaneous detection of Corynebacterium diphtheriae and differentiation between non-toxigenic and toxigenic isolates. J Med Microbiol 57, 1438-1439.

Pimenta, F. P., Souza, M. C., Pereira, G. A., Hirata, R., Jr, Camello, T. C. F. \& Mattos-Guaraldi, A. L. (2008b). DNase test as a novel approach for the routine screening of Corynebacterium diphtheriae. Lett Appl Microbiol 46, 307-311.

Polotsky, Y., Nataro, J. P., Kotler, D., Barrett, T. J. \& Orenstein, J. M. (1997). HEp-2 cell adherence patterns, serotyping, and DNA analysis of Escherichia coli isolates from eight patients with AIDS and chronic diarrhea. J Clin Microbiol 35, 1952-1958.

Rao, R. S., Karthika, R. U., Singh, S. P., Shashikala, P., Kanungo, R., Jayachandran, S. \& Prashanth, K. (2008). Correlation between biofilm production and multiple drug resistance in imipenem resistant clinical isolates of Acinetobacter baumannii. Indian J Med Microbiol 26, 333-337.
Rigdon, R. H. (1970). Hemolysis associated with plastics - a histopathologic study with polyurethane. J Biomed Mater Res 4, 57-71.

Rolston, K. V. I., Bodey, G. P. \& Safdar, A. (2007). Polymicrobial infection in patients with cancer: an underappreciated and underreported entity. Clin Infect Dis 45, 228-233.

Rosenberg, M. (1981). Bacterial adherence to polystyrene: a replica method of screening for bacterial hydrophobicity. Appl Environ Microbiol 42, 375-377.

Scaletsky, I. C., Pedroso, M. Z., Oliva, C. A., Carvalho, R. L., Morais, M. B. \& Fagundes-Neto, U. A. (1999). Localized adherence-like pattern as a second pattern of adherence of classic enteropathogenic Escherichia coli to HEp-2 cells that is associated with infantile diarrhea. Infect Immun 67, 3410-3415.

Schiffl, H., Mucke, C. \& Lang, S. M. (2004). Exit-site infections by non-diphtheria corynebacteria in CAPD. Perit Dial Int 24, 454-459.

Silva De Souza, S. M., Hirata, R., Jr, Moreira, L. O., Gomes, M. L., Braga De Andrade, A. F., Bernardo-Filho, M. \& Mattos-Guaraldi, A. L. (2003). Influence of stannous chloride on the adhesive properties of Corynebacterium diphtheriae strains. Int J Mol Med 12, 657-661.

Soriano, F., Ponte, C. \& Galiano, M. J. (1993). Adherence of Corynebacterium urealyticum (CDC group D2) and Corynebacterium jeikeium to intravascular and urinary catheters. Eur J Clin Microbiol Infect Dis 12, 453-456.

Soriano, F., Huelves, L., Naves, P., Rodriguez-Cerrato, V., Del Prado, G., Ruiz, V. \& Ponte, C. (2008). In vitro activity of ciprofloxacin, moxifloxacin, vancomycin and erythromycin against planktonic and biofilm forms of Corynebacterium urealyticum. J Antimicrob Chemother 63, 353-356.

Stepanovic, S., Vukovic, D., Davic, I., Savic, B. \& Svabic-Vlahovic, M. (2000). A modified microtiter-plate test for quantification of staphylococcal biofilm formation. J Microbiol Methods 40, 175-179.

Stewart, P. S. \& Costerton, J. W. (2001). Antibiotic resistance of bacteria in biofilms. Lancet 358, 135-138.

Suzuki, T., Lihara, H., Uno, T., Hara, Y., Ohkusu, K., Hata, H., Shudo, M. \& Ohashi, Y. (2007). Suture-related keratitis caused by Corynebacterium macginleyi. J Clin Microbiol 45, 3833-3836.

Teixido, J., Arias, N., Tarrats, L. \& Romero, R. (2007). The microbial pattern of the catheter exit-site infection in peritoneal dialysis: a nondiphtheria corynebacteria emergence? Nefrologia 27, 350-358.

Wakimoto, N., Nishi, J., Sheikh, J., Nataro, J. P., Sarantuya, J., Iwashita, M., Manago, K., Tokuda, K., Yoshinaga, M. \& Kawano, Y. (2004). Quantitative biofilm assay using a microtiter plate to screen for enteroaggregative Escherichia coli. Am J Trop Med Hyg 71, 687-690.

Wang, C. C., Mattson, D. \& Wald, A. (2001). Corynebacterium jeikeium bacteremia in bone marrow transplant patients with Hickman catheters. Bone Marrow Transplant 27, 445-449. 